\title{
Consecutive salinomycin treatment reduces doxorubicin resistance of breast tumor cells by diminishing drug efflux pump expression and activity
}

\author{
ADAM HERMAWAN, ERNST WAGNER and ANDREAS ROIDL \\ Pharmaceutical Biotechnology, Department of Pharmacy, Ludwig-Maximilian University of Munich, \\ D-81377 Munich, Germany
}

Received September 17, 2015; Accepted November 17, 2015

DOI: $10.3892 / o r .2015 .4509$

\begin{abstract}
Chemoresistance is a major challenge for the successful therapy of breast cancer. The discovery of salinomycin as an anticancer stem cell drug provides progress in overcoming chemoresistance. However, it remains to be elucidated whether salinomycin treatment is able to sensitize cancer cells to chemotherapeutic drugs. In the present study, we consecutively treated epithelial MCF-7 and BT-474 breast cancer cells as well as mesenchymal MDA-MB 231 and MDA-MB 436 cells with salinomycin, and analyzed the gene expression of the two prominent multiple drug resistance (MDR) genes, MDR1 and BCRP1. We found that repeated treatment with salinomycin generated resistance against this drug in all cell lines and increased the chemosensitivity towards doxorubicin. Drug efflux pump gene expression and pump activity of MDR1 and BCRP1 were downregulated in almost all cell lines, except for MDR1 in the MDA-MB 231 cells. Consequently, the intracellular doxorubicin accumulation was increased compared to the respective parental cells. Our findings suggest a novel treatment option for MDR tumors by sensitizing these tumors via salinomycin pretreatment.
\end{abstract}

\section{Introduction}

The WHO reported that breast cancer is one of the leading causes of death and the most common cancer among women worldwide (1). Important progress has been made in regards to breast cancer treatment in recent years, including novel targeted therapies (2). However, classical chemotherapy is still most frequently used in the clinic and thus, chemoresistance is a severe complication of breast cancer therapy (3-6).

Correspondence to: Dr Andreas Roidl, Pharmaceutical Biotechnology, Department of Pharmacy, Ludwig Maximilian University of Munich, Butenandtstrasse 5-13, D-81377 Munich, Germany

E-mail: andreas.roidl@cup.uni-muenchen.de

Key words: salinomycin, doxorubicin, multiple drug resistance, breast cancer, chemotherapy
Approximately $30 \%$ of early breast cancer patients face a relapse involving increased resistance to chemotherapeutics and metastasis $(7,8)$. Moreover, in later stages of breast cancer, the response rates of classical chemotherapeutics, e.g. taxanes and anthracyclines, have declined from 70 to $20-30 \%$. Accordingly, research on drug resistance development and solutions to overcome drug resistance are urgently needed to improve the efficacy of chemotherapeutic drugs.

Salinomycin is an ionophore antibiotic, introduced in 2009 as a cancer stem cell targeting drug (9). Salinomycin also inhibits cell survival, growth, migration and invasion of human non-small lung cancer cells (10). Studies have shown that salinomycin induces cell death in breast (11), ovarian (12), as well as in head and neck cancer cells (13). Moreover, salinomycin was found to inhibit cell growth in prostate (14) and pancreatic cancer cells (15). Salinomycin treatment additionally reduces metastasis formation by decreasing the migratory capability of cancer cells (16).

Further studies of salinomycin on overcoming drug resistance have also been conducted. Fuchs et al have shown that salinomycin overcomes $\mathrm{ABC}$ transporter-mediated multidrug- and apoptosis-resistance in human cancer cells $(17,18)$. Salinomycin co-treatment was also found to increase doxorubicin and etoposide cytotoxicity by enhancing DNA damage and downregulating p21 (19), to increase doxorubicin cytotoxicity in soft tissue sarcomas (20), to elevate apoptosis in cisplatin-resistant colorectal cancer cells by accumulating reactive oxygen species (21), and to induce apoptosis in cisplatin-resistant human ovarian cancer cells (22). A combination of salinomycin and trail circumvents trail resistance in glioma cells (23). We have previously shown that a combination of salinomycin and trastuzumab efficiently targets cancer stem cells and Her-2-positive cancer cells (24). Moreover, a recent study by Kim et al have shown that combined treatment of salinomycin and doxorubicin enhances the cytotoxicity in multidrug resistant MCF-7/MDR human breast cancer cells by decreasing the efflux of doxorubicin (25).

In the present study, we investigate whether consecutive treatment of salinomycin, i.e. analogous to the treatment regimen in the clinic, sensitizes cancer cells to standard chemotherapeutic drug treatment. We demonstrate that consecutive salinomycin treatment generates salinomycin-resistant cells 
with increased susceptibility to doxorubicin. Furthermore, salinomycin-resistant cells exhibit a downregulation of the prominent multiple drug resistance (MDR) proteins MDR1 and BCRP1. The reduced expression of these efflux pumps decreases the overall pump activity, which leads to an intracellular accumulation of drugs, i.e. doxorubicin and eventually increased cytotoxicity. Therefore, consecutive salinomycin treatment sensitizes the cancer cells to doxorubicin.

\section{Materials and methods}

Cell lines and culture. MCF-7, BT-474, MDA-MB 231 and MDA-MB 436 human breast cancer cells were purchased from ATCC. MCF-7 cells were grown in Dulbecco's modified Eagle's medium (DMEM) high glucose supplemented with $20 \%$ fetal calf serum (FCS) (both from Gibco) and $2 \mathrm{mM}$ L-glutamine at $37^{\circ} \mathrm{C}$ and $5 \% \mathrm{CO}_{2}$. BT-474 cells were grown in RPMI-1640 medium (supplemented with 10\% FCS) and $2 \mathrm{mM}$ L-glutamine (both from Gibco) at $37^{\circ} \mathrm{C}$ and $5 \% \mathrm{CO}_{2}$. MDA-MB 231 and MDA-MB 436 cells were grown in L-15 Leibovitz's medium (Biochrom) supplemented with $10 \%$ FCS and $2 \mathrm{mM}$ glutamine at $37^{\circ} \mathrm{C}$ without $\mathrm{CO}_{2}$. Cells were routinely tested and confirmed as mycoplasm-free.

Molecular evolution assay. Cells (80\% of confluency) were treated with salinomycin (Sigma-Aldrich, Germany) for $72 \mathrm{~h}$ as previously described (26). The concentration of salinomycin was $500 \mathrm{nM}$ for the MCF-7 and BT-474 cells and $50 \mathrm{nM}$ for the MDA-MB 231 and MDA-MB 436 cells as mesenchymal cells display increased sensitivity to salinomycin $(16,27)$. Thereafter, the treatment medium was replaced with fresh medium and cells were grown until recovery (80\% of confluency). As soon as recovered, the cells were split for RNA analysis, as well as for the next treatment, and also seeded for the cell viability assay. $\mathrm{R} 0$ represents the untreated control cell line (parental cells), whereas R1, R2, R3, R4 and R5 represent cells that were treated for one, two, three, four and five times with salinomycin, respectively.

Cell viability assay. For the cytotoxicity assays, $5 \times 10^{3}$ cells were seeded into a 96-well plate (TPP) and incubated for $24 \mathrm{~h}$. Cells were then treated with various concentrations of salinomycin, doxorubicin or verapamil (Sigma-Aldrich) for $72 \mathrm{~h}$, followed by CellTiter-Glo assay (Promega, Germany) according to the manufacturer's instructions. Three replicas were analyzed.

The $\mathrm{EC}_{50}$ was determined by GraphPad Prism software. The drug concentration was transformed into log scale, and a nonlinear regression (curve fit) was made.

RNA extraction and quantitative RT-PCR. Total RNA was extracted and isolated from cells using the miRCURY ${ }^{\mathrm{TM}}$ RNA isolation kit (Exiqon, Denmark). RNA was then reverse transcribed to cDNA from $1.0 \mu \mathrm{g}$ of total RNA using the Transcriptor First Strand cDNA synthesis kit (Roche). Realtime PCR was then performed with the Light Cycler ${ }^{\circledR} 480$ using the Master Probes kit and the Universal ProbeLibrary (UPL) (all from Roche). All protocols were performed according to the instructions of the manufacturer. RT-PCR was performed using the following primers and UPLs: MDR1, UPL probe \#7, left primer, caagcatctgccaaaacctc and right primer, ctgggtttcccctgtaaat; BCRP1, UPL probe \#56, left primer, tggettagactcaagcacagc and right primer, tcgtccetgcttagacatcc; GAPDH, UPL probe \#45, left primer, tccactggcgtcttcacc and right primer, ggcagagatgatgaccetttt. GAPDH was used as an internal control. The results were analyzed using comparative threshold cycle ( $\Delta \Delta \mathrm{CT}$ method).

Internalization of doxorubicin. Cells were treated with $10 \mu \mathrm{M}$ of doxorubicin for $3 \mathrm{~h}$. The medium was replaced with fresh medium $1 \mathrm{~h}$ prior to imaging and FACS analysis. To perform FACS analysis, cells were prepared by trypsinization and measured with a CyAn ${ }^{\mathrm{TM}}$ ADP flow cytometer (DakoCytomation). Doxorubicin intracellular levels were analyzed using FlowJo software (Tree Star).

Statistical analysis. All data are presented as mean \pm SD, and were analyzed using GraphPad Prism 5.0 software.

\section{Results}

Molecular evolution assays generate salinomycin-resistant cancer cells. To mimic clinical applications of chemotherapeutics in vitro, we performed repeated salinomycin treatment of the epithelial breast cancer cell lines MCF-7 and BT-474, as well as of the mesenchymal breast cancer cell lines MDA-MB 231 and MDA-MB 436. We found that the consecutive treatment resulted in enhanced formation of salinomycin-resistant cells. The $\mathrm{IC}_{50}$ value of salinomycin increased during the treatment cycles, both in the epithelial MCF-7 (Fig. 1A) and BT-474 cells (Fig. 1B) as well as in the mesenchymal MDA-MB 231 (Fig. 1C) and MDA-MB 436 (Fig. 1D) cells. Furthermore, the resistant cells also displayed a decreased proliferation compared to parental cells, as indicated by a longer period of time to reach $80 \%$ confluency (Fig. 1A-D, right panel).

Salinomycin-resistant cells show enhanced sensitivity for doxorubicin. Since salinomycin acts on different targets than classical chemotherapeutics, we studied the cross-resistance to doxorubicin $(5 \mu \mathrm{M})$ by performing cytotoxicity assay on both resistant (R5) and parental cells (R0). The results revealed that all of the MCF-7, BT-474, MDA-MB 231 and MDA-MB 436 salinomycin-resistant cells (R5) became more sensitive to doxorubicin compared to the parental cells (R0) (Fig. 2A). Accordingly, a similar effect was observed when analyzing the $\mathrm{IC}_{50}$ values for doxorubicin for the R0 and R5 cells (Fig. 2B). Cells displayed a 2- to 7-fold increase in doxorubicin sensitivity for all of the corresponding R5 cells (Fig. 2C).

Drug efflux pumps are downregulated in salinomycinresistant cells. A common mechanism in drug resistance is the upregulation and increased activity of efflux pumps, which play an important role in absorbing, distributing and eliminating drugs from the cells. We analyzed whether a decrease in multiple drug resistance (MDR) is responsible for the increased doxorubicin sensitivity in R5 cells. We therefore first determined the basal expression of the prominent efflux pump genes MDR1 and BCRP1 in all parental cells (R0) by quantitative RT-PCR. MDR1 was highly expressed in the 

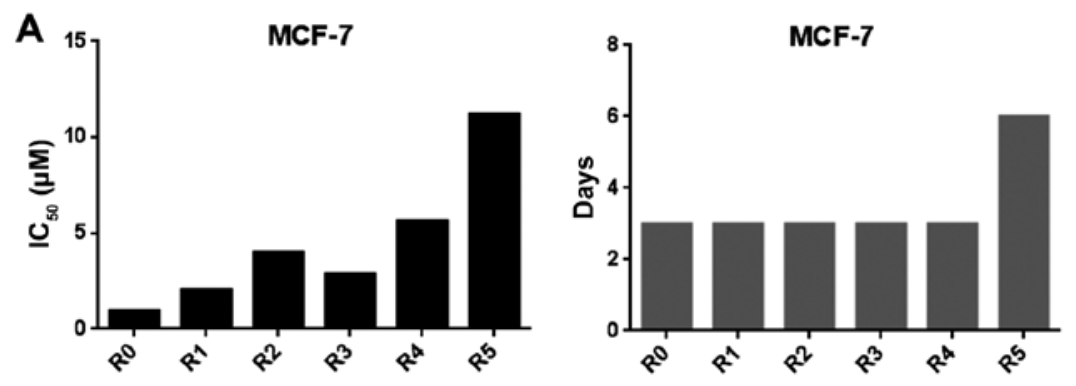

\begin{tabular}{ccc}
\hline & $\mathrm{IC}_{50}(\mathrm{\mu M})$ & $\begin{array}{c}\text { Days to } 80 \% \\
\text { confluency }\end{array}$ \\
\hline R0 & 0.92 & 3 \\
R1 & 2.06 & 3 \\
R2 & 4.01 & 3 \\
R3 & 2.84 & 3 \\
R4 & 5.62 & 3 \\
R5 & 11.2 & 6 \\
\hline
\end{tabular}
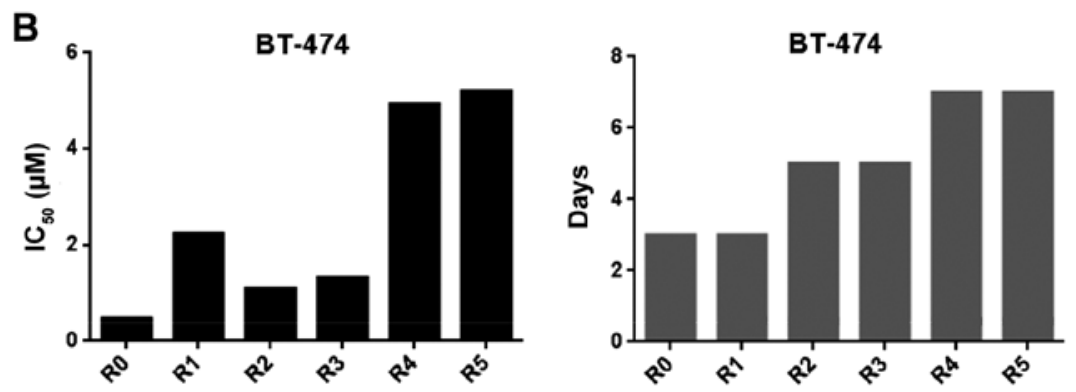

\begin{tabular}{ccc}
\hline & $\mathrm{IC}_{80}(\mu \mathrm{M})$ & $\begin{array}{c}\text { Days to } 80 \% \\
\text { confluency }\end{array}$ \\
\hline R0 & 0.47 & 3 \\
R1 & 2.23 & 3 \\
R2 & 1.09 & 5 \\
R3 & 1.32 & 5 \\
R4 & 4.92 & 7 \\
R5 & 5.20 & 7 \\
\hline
\end{tabular}
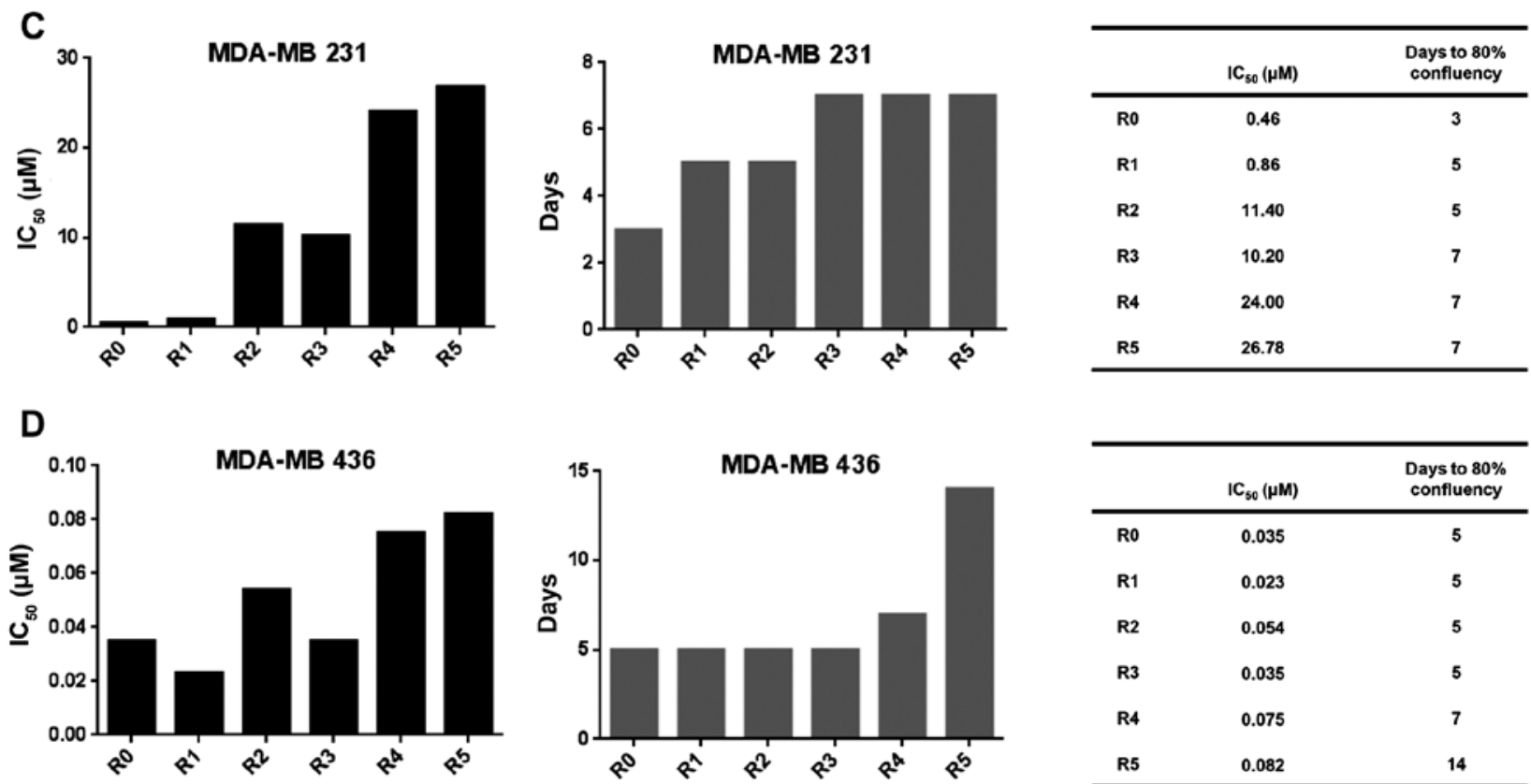

\begin{tabular}{ccc}
\hline & $\mathrm{CC}_{\text {50 }}(\mu \mathrm{M})$ & $\begin{array}{c}\text { Days to } 80 \% \\
\text { confluency }\end{array}$ \\
\hline R0 & 0.035 & 5 \\
R1 & 0.023 & 5 \\
R2 & 0.054 & 5 \\
R3 & 0.035 & 5 \\
R4 & 0.075 & 7 \\
R5 & 0.082 & 14 \\
\hline
\end{tabular}

Figure 1. Molecular evolution assays generate salinomycin-resistant cancer cells. $\mathrm{IC}_{50}$ values of salinomycin during the molecular evolution assays (left panel) and the number of days to reach $80 \%$ confluency after first cell splitting (central panel). The right panel presents the corresponding values in tabular form. (A) MCF-7, (B) BT-474, (C) MDA-MB 231, (D) MDA-MB 436 cells. To determine the $\mathrm{IC}_{50}$ values, the cells were treated with various concentrations of salino-

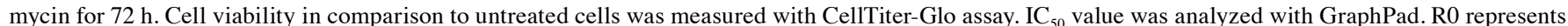
the parental cells, whereas R1, R2, R3, R4 and R5 represent cells that were treated with salinomycin for one, two, three, four and five times, respectively.

BT-474 cells, whereas BCRP1 was highly expressed in the MDA-MB 231 cells (Fig. 3A). Furthermore, the MCF-7 cells had the lowest efflux pump expression among the analyzed cells. To ascertain whether the consecutive treatment of salinomycin influences the expression of the drug efflux pump, we measured MDR1 and BCRP1 expression in the salinomycin-resistant cells (R5) and made a comparison to respective parental cells (R0). Both MDR1 and BCRP1 were downregulated in the MCF-7 and MDA-MB 436 resistant cells (Fig. 3B and E). In the BT-474 salinomycin-resistant cells, MDR1 was downregulated, whereas BCRP1 was upregulated (Fig. 3C) and in the MDA-MB 231 salinomycinresistant cells (Fig. 3D), MDR1 was upregulated and BCRP1 displayed decreased expression.

Blocking the efflux pump activity affects chemoresistance mainly of parental cells. In order to analyze whether the decrease in efflux pump expression affects the pump activity, we blocked these pumps with the selective inhibitor verapamil, and measured cytotoxicity upon doxorubicin treatment. In the MCF-7 parental cells, addition of verapamil increased the doxorubicin-induced cytotoxicity, whereas in the 

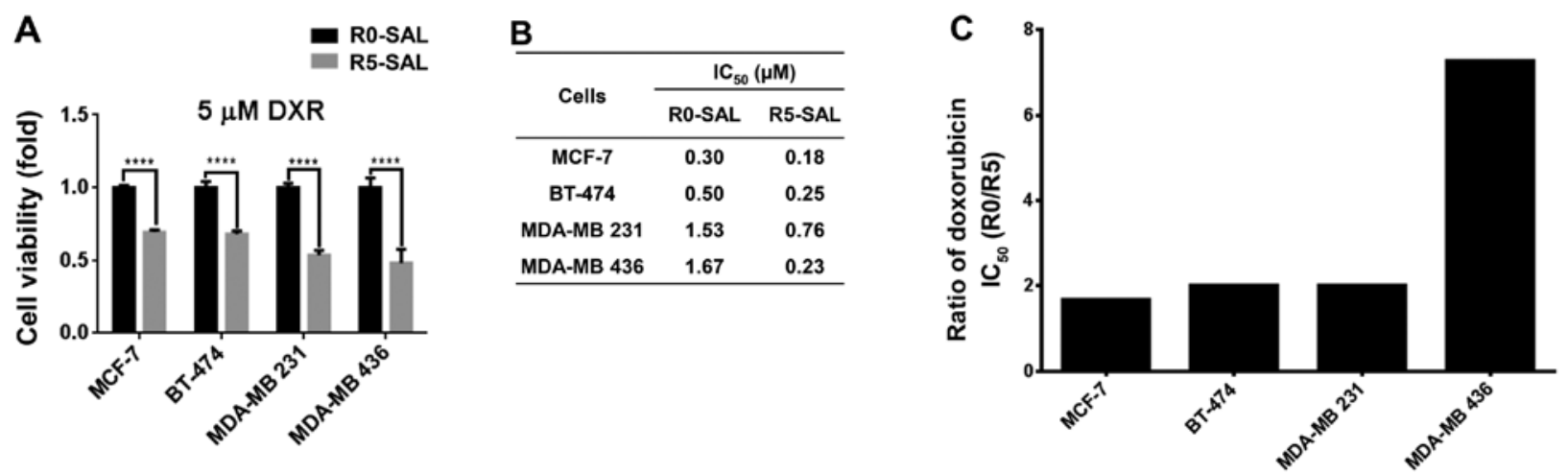

Figure 2. Salinomycin-resistant cells show enhanced sensitivity for doxorubicin. Susceptibility of MCF-7, BT-474, MDA-MB 231 and MDA-MB 436 R0 and R5-SAL cells to (A) doxorubicin (DXR) $(5 \mu \mathrm{M}, 72 \mathrm{~h})$. (B) $\mathrm{IC}_{50}$ values for DXR in the R0 and R5-SAL resistant cells. Cancer cells of R0 and R5-SAL were treated with indicated concentrations of salinomycin or DXR for $72 \mathrm{~h}$. Cell viability was determined by CellTiter-Glo assay in comparison to the untreated cells. $\mathrm{IC}_{50}$ values for DXR were analyzed with GraphPad software. Results are also shown in $(\mathrm{C})$ as the ratio of $\mathrm{IC}_{50}(\mathrm{R} 0: \mathrm{R} 5)$. Statistical analysis was conducted using the Student's t-test. ${ }^{* * * *} \mathrm{p}<0.0001$, respectively.

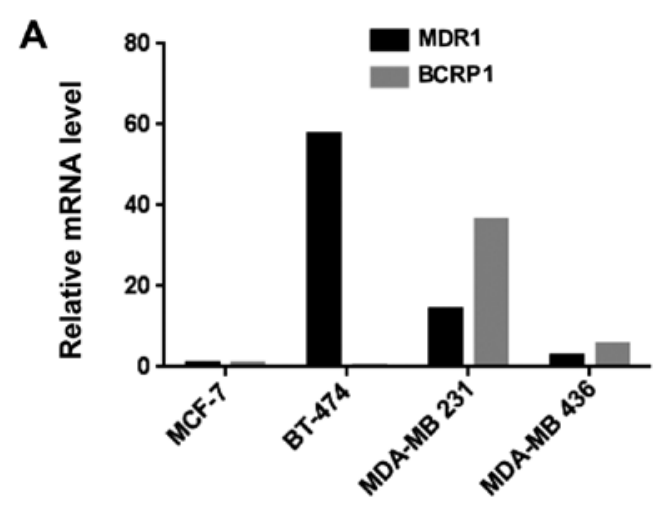

B

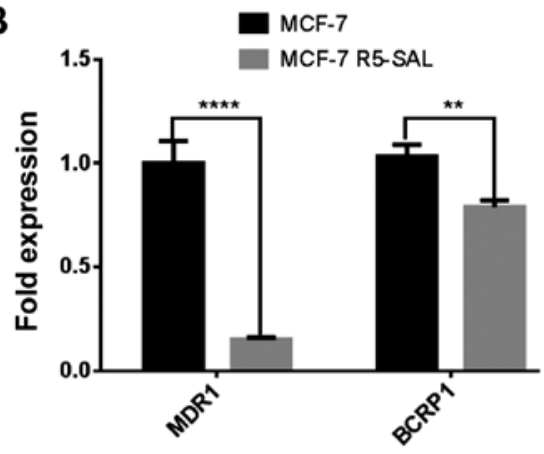

D

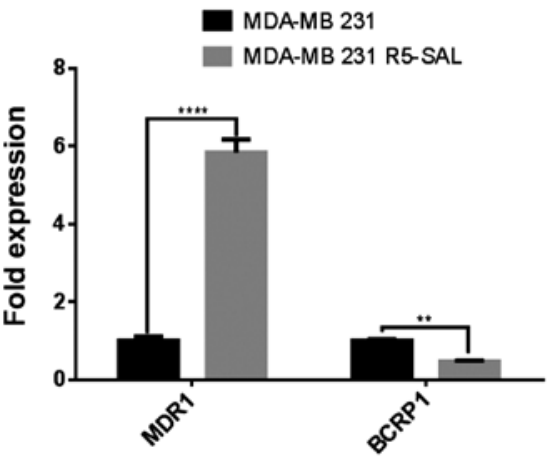

C

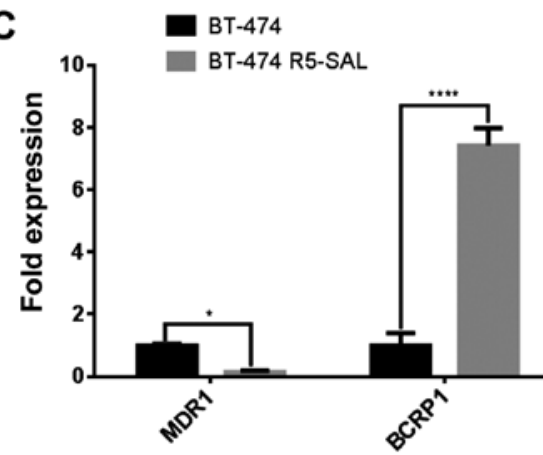

E

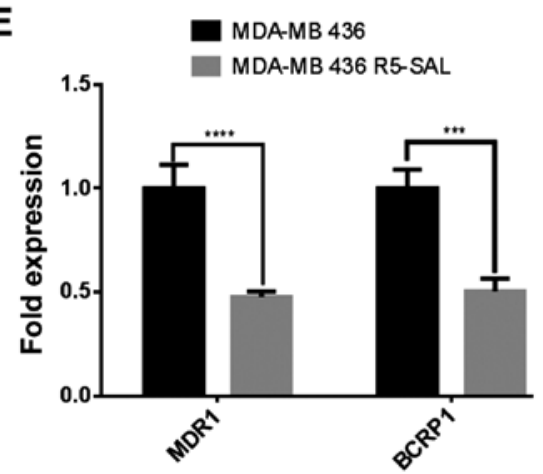

Figure 3. Drugs efflux pumps are downregulated in salinomycin-resistant cells. (A) MDR1 and BCRP1 expression in MCF-7, BT-474, MDA-MB 231 and MDA-MB 436 parental cells as determined by qRT-PCR. (B-E) Relative expression levels of MDR1 and BCRP1 in salinomycin-resistant (R5-SAL) cells compared to parental cells (R0) of: (B) MCF-7, (C) BT-474, (D) MDA-MB 231, (E) MDA-MB 436 cell lines. Gene expression was determined by qRT-PCR. GAPDH was used as an internal control. Results represent the average of three independent experiments (mean \pm SD). Statistical analyses were conducted using the Student's t-test. ${ }^{*} \mathrm{p}<0.05,{ }^{* *} \mathrm{p}<0.01,{ }^{* * *} \mathrm{p}<0.001,{ }^{* * * * *} \mathrm{p}<0.0001$, respectively. 

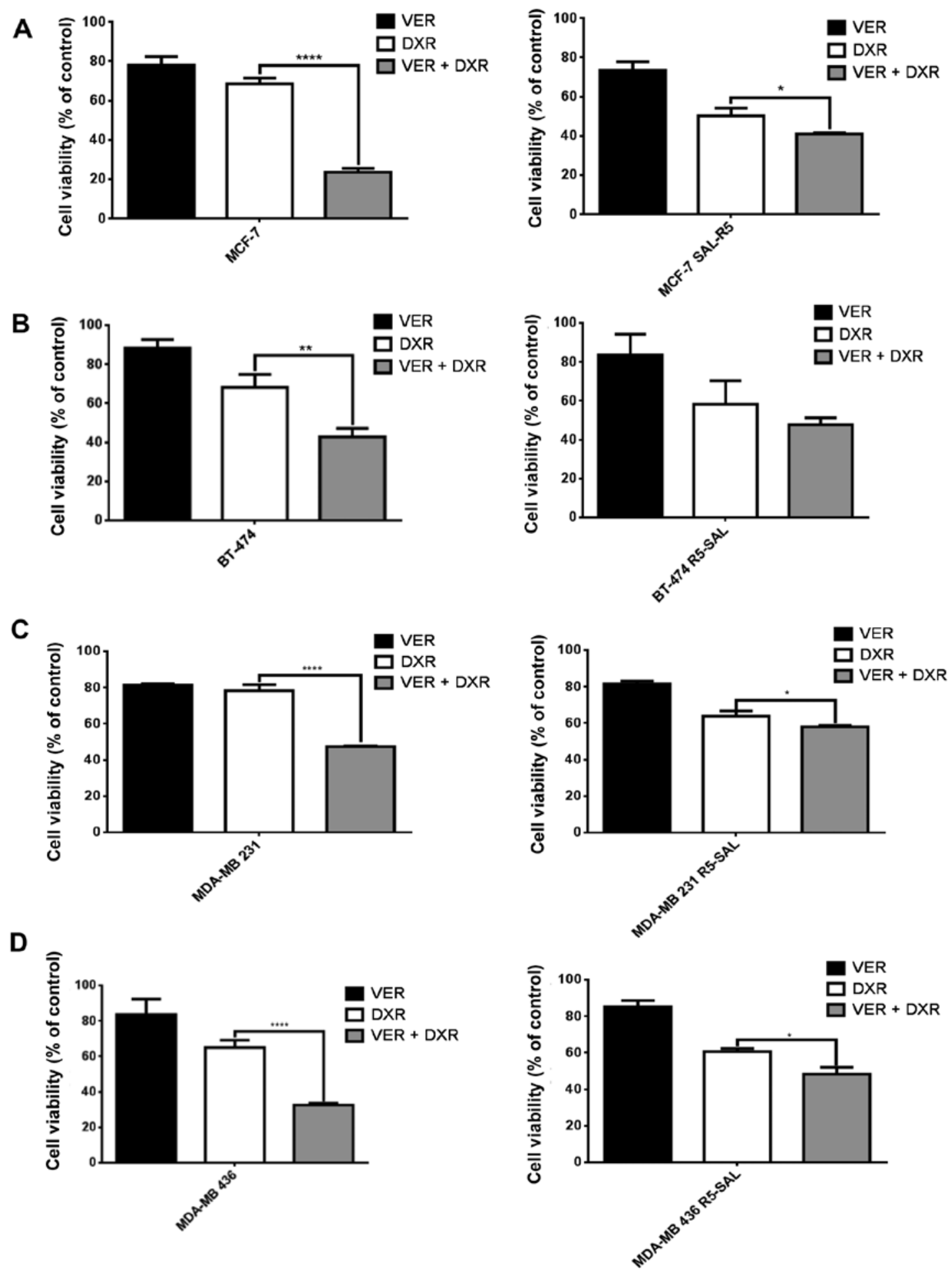

Figure 4. Blocking the efflux pumps activity affects chemoresistance mainly of parental cells. Susceptibility of (A) MCF-7, (B) BT-474, (C) MDA-MB 231 and (D) MDA-MB 436 parental R0 or R5 salinomycin-resistant (R5-SAL) cells to doxorubicin (DXR) single treatment or in combination with verapamil (VER + DXR). Cancer cells of R0 and R5 were treated for $72 \mathrm{~h}$ with the respective $\mathrm{IC}_{50}$ value of DXR (as shown in Fig. $2 \mathrm{C}$ ) and with or without $10 \mu \mathrm{M}$ of verapamil. Cell viability is depicted as a percentage in comparison to untreated cells and was measured with CellTiter-Glo assay. Results represent the average of three independent experiments (mean $\pm \mathrm{SD}$ ). Statistical analyses were conducted using the Student's t-test. ${ }^{*} \mathrm{p}<0.05 ;{ }^{* *} \mathrm{p}<0.01,{ }^{* * * *} \mathrm{p}<0.0001$, respectively.

salinomycin-resistant cells addition of verapamil had almost no effect (Fig. 4A). Similar effects were also observed in the cell lines BT-474 (Fig. 4B), MDA-MB 231 (Fig. 4C) and MDA-MB 436 (Fig. 4D), and their corresponding salinomycinresistant descendants. Thus, the inhibition of the efflux pumps increased the doxorubicin-induced cytotoxicity mainly in the parental (R0) cells.

Salinomycin-resistant cells show increased intracellular doxorubicin accumulation. As salinomycin-resistant cells 
A
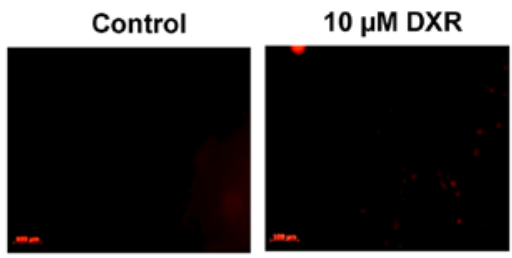

MCF-7
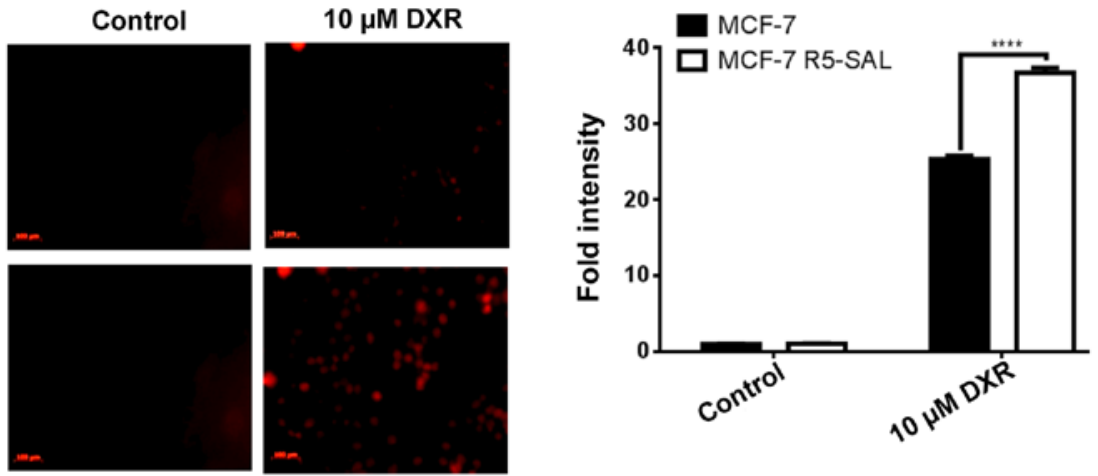

B
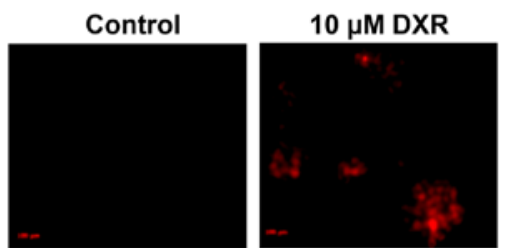

BT-474 R5-SAL
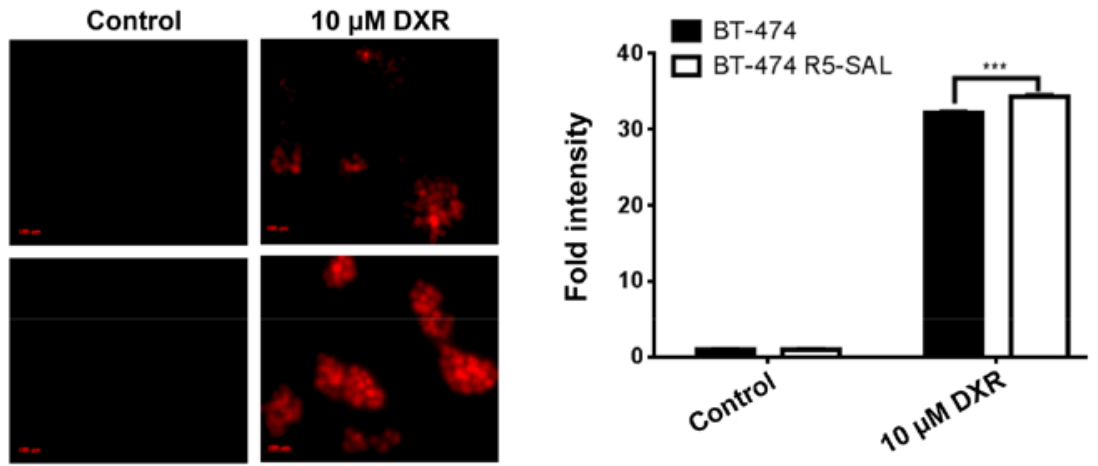

C

MDA-MB 231
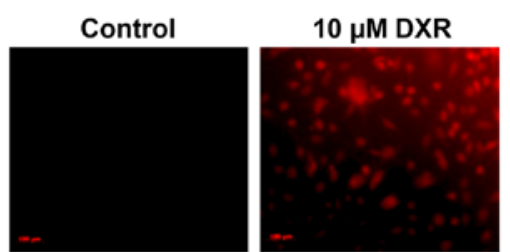

MDA-MB 231 R5-SAL
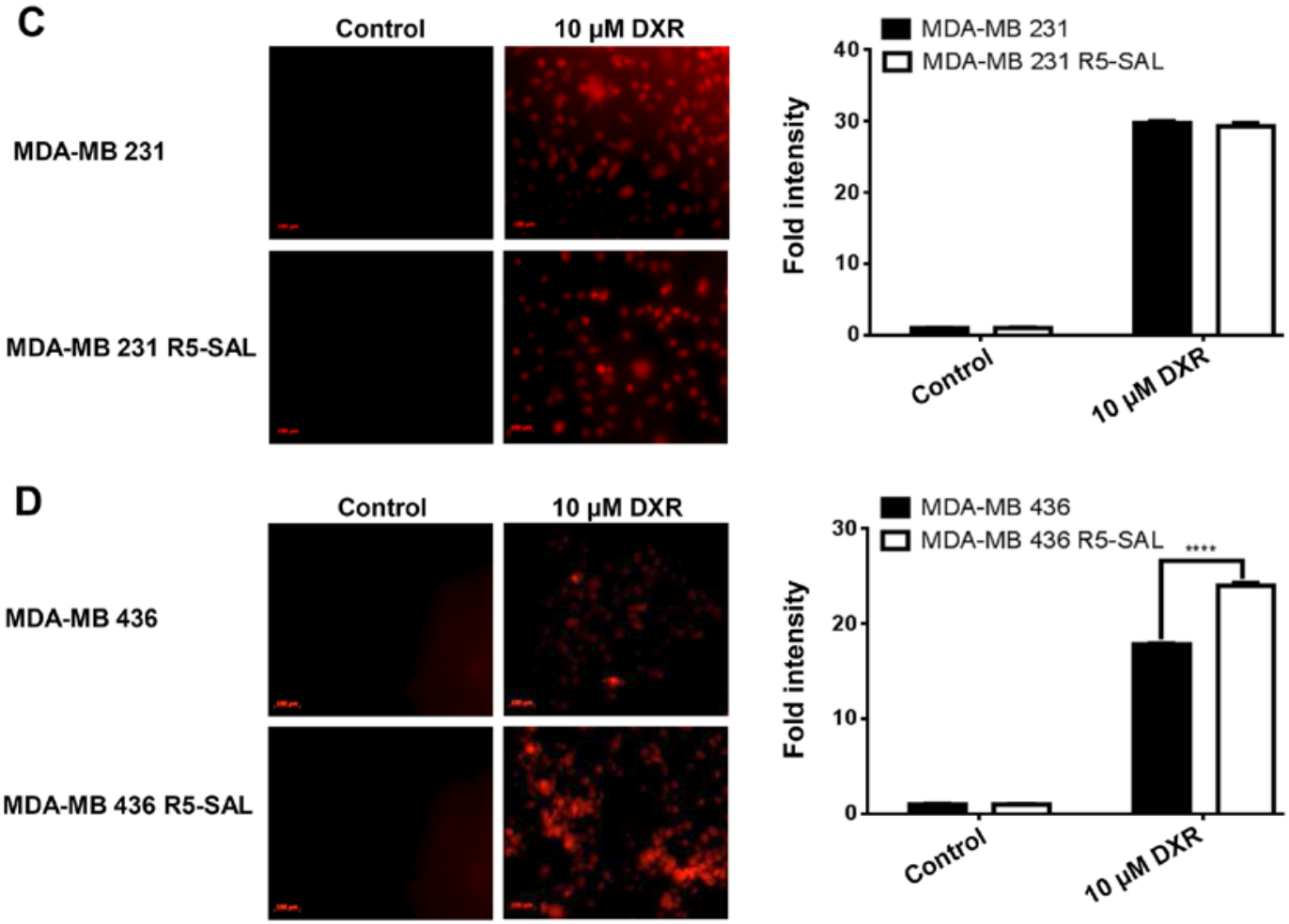

Figure 5. Salinomycin-resistant cells show increased intracellular doxorubicin accumulation. Image analysis of intracellular doxorubicin (DXR) (left panel) and FACS analysis of intracellular DXR in (A) MCF-7, (B) BT-474, (C) MDA-MB 231 and (D) MDA-MB 436 parental R0 and R5 salinomycin-resistant (R5SAL) cells. Cells were treated with $10 \mu \mathrm{M}$ of DXR for $3 \mathrm{~h}$. DXR was removed from the medium $1 \mathrm{~h}$ prior to image analysis and FACS. For flow cytometry, cells were trypsinized, diluted in PBS and analyzed by FACS. Results are shown as the relative mean fluorescence to respective untreated controls and represent the average of three independent experiments (mean $\pm \mathrm{SD}$ ). Statistical analyses were conducted using the Student's t-test. ${ }^{* * * *} \mathrm{p}<0.001,{ }^{* * * * *} \mathrm{p}<0.0001$, respectively.

downregulated the gene expression of drug efflux pumps and thus their activity, we also analyzed whether these cells show enhanced intracellular drug accumulation. We treated both the parental (R0) and the salinomycin-resistant (R5) cells with doxorubicin and studied the internalization of doxorubicin by image analysis (Fig. 5A), and by measuring the intracellular doxorubicin level with FACS. We observed an enhanced accumulation of doxorubicin in the 
MCF-7, BT-474 and MDA-MB 436 salinomycin-resistant cells (R5) (Fig. 5A, B and D) compared to parental cells (R0). MDA-MB 231 salinomycin-resistant cells (Fig. 5C) showed less accumulation of doxorubicin than parental cells (R0), which is in line with the enhanced MDR1 expression.

\section{Discussion}

Chemoresistance is still a major threat to successful cancer therapy. To investigate novel mechanisms and drugs circumventing therapy resistance, we consecutively treated epithelial and mesenchymal breast cancer cells with salinomycin and generated salinomycin-resistant cells. Numerous studies on cancer drug resistance utilize continuous drug treatment with increasing concentrations of the drugs (28-31). Unlike previous studies on salinomycin and doxorubicin $(25,32)$, we consecutively treated breast cancer cells with the same concentration of salinomycin and gave the cells time to recover after each treatment round. This procedure was performed for five treatment cycles. Our settings sought to mimic the application process of chemotherapeutics in the clinic. There, the patient, and thus the tumor or residual tumor cells, also undergo a recovery phase during treatment cycles, as chemotherapy is only tolerated to a certain extent. The resistance formation in our assay exhibited no linear increase of the $\mathrm{IC}_{50}$ value for salinomycin. We, therefore, concluded that the observed resistance formation is based on the principle of clonal selection. According to the clonal evolution theory, tumor cells display heterogeneity and genetic instability. When treated with chemotherapy, selection pressure is applied and some of the cells will survive the treatment. These cells will form a new polyclonal cell population with various new genetic predispositions (33). After each round of the molecular evolution assay, different cell population may have survived and thus no linear increase in the $\mathrm{IC}_{50}$ value was detected in our assay. Additionally, many different resistance mechanism possibly exist in parallel caused by the clonal selection in the molecular evolution assay. For example, we observed decreasing cell proliferation, indicating that salinomycin treatment eradicates fast growing cell populations. Unlike in several molecular evolution assays we performed with doxorubicin, the growth retardation here was only modest. A recent study by Kopp et al also showed that consecutive treatment of mesenchymal breast cancer cells with salinomycin resulted in resistance formation by mesenchymal to epithelial transition (MET) (27).

Notably, we observed that the salinomycin-resistant cells exhibited increased sensitivity to doxorubicin in both epithelial and mesenchymal tumor cells. As it was reported that combinational, i.e. simultaneous treatment of tumor cells with salinomycin and doxorubicin, cisplatin or etoposide increased the cytotoxicity $(19,21)$, we hypothesized that in our assay the sensitivity of the salinomycin-resistant cells to other drugs may be increased as well.

The most important drug resistance mechanism is the upregulation and increased activity of ABC-transporters (ATP binding cassette transporter) (34). Among these efflux pumps in charge of decreasing intracellular drug levels are p-glycoprotein [encoded by multidrug resistance 1 (MDR1) gene], breast cancer resistance protein (encoded by the BCRP1 gene), and multidrug resistance-associated proteins (encoded by MRP genes) $(28,35$ 37). The ABC transporter family consists of membrane proteins that translocate a variety of substrates across extracellular and intracellular membranes (28). They play an important role in absorbing, distributing and eliminating drugs from the cells (38). Hence, the upregulation of efflux pumps decreases intracellular drug accumulation and increases drug resistance leading to multiple drug resistance (MDR) (39).

Several MDR reversing agents modify cell membrane fluidity and increase cell membrane permeability (40). Salinomycin is able to circumvent MDR by acting as an ionophore. Salinomycin, a transmembrane $\mathrm{Na}^{+} / \mathrm{K}^{+}$ionophore, is embedded in biological membranes $(41,42)$, and thus by changing membrane integrity it is able to inhibit the activity of drug efflux pumps. Additionally, salinomycin disturbs the intracellular balance of ions by increasing the sodium ion level (42-44). In the present study, we showed that MDR1 and BCRP1 were downregulated after repeated salinomycin treatment. The decrease in the expression of MDR proteins could occur via a direct and indirect mechanism. On the one hand, salinomycin was found to be an anticancer stem cell drug. One of the hallmarks of cancer stem cells is an increase in efflux pump activity (45). That is why cancer stem cells are thought to be present in the so-called side-population (46). Salinomycin eradicates this population, as seen by a decreased expression of stem cell markers (data not shown) thereby increasing the non-cancer stem cell fraction with low efflux pump expression. Due to the cyclic drug treatment, the offspring of these efflux pump-positive cancer stem cells, which usually accounts for less than $10 \%$ of the cell population, may also die out over time. Whether the killing of cancer stem cells and their offspring accounts for such a strong indirect effect in gene expression of efflux pumps and eventually doxorubicin sensitivity, remains to be elucidated. On the other hand, efflux pumps may be important for the direct execution of the salinomycin cytotoxicity, as they regulate the intracellular balance of molecules.

In contrast to the breast cancer cell lines MCF7 and MDA-MB 436, where MDR1 and BCRP1 expression was decreased upon consecutive salinomycin treatment, we observed an upregulation of some of these proteins in the BT-474 and MDA-MB 231 cells. BCRP1 for example was increased 7-fold in the BT-474 cells. However, the BCRP1 level in the BT-474 parental cells was very low compared to the other cell lines, thus the upregulation in salinomycin-resistant cells did not substantially influence the efflux pump activity, as shown by blocking the pump activity with verapamil. Doxorubicin is a substrate of p-glycoprotein (28), while verapamil acts as competitive inhibitor by directly binding to p-glycoprotein on a specific site (47), thereby preventing doxorubicin efflux across the cell membrane. In contrast to the BT474 cell line, MDA-MB 231 salinomycin-resistant cells displayed a 6-times higher level of MDR1 which resulted in increased efflux activity. Therefore, the increased doxorubicin sensitivity was due to a different mechanism. Since ABC transporters are downregulated in salinomycin-resistant cells, we observed an enhanced doxorubicin accumulation. Doxorubicin induces DNA damage by generating malondialdehyde-DNA adducts induced by free radicals (48). Hence, we suppose increased DNA damage in the salinomycin-resistant cells that finally led to cell death. 
In conclusion, we demonstrated that consecutive salinomycin treatment generates salinomycin-resistant tumor cells and increases their susceptibility to doxorubicin by downregulating MDR1 and BCRP1 gene expression (except for MDR1 in MDA-MB 231 cells). These findings suggest salinomycin pretreatment of chemoresistant tumors in order to resensitize them to chemotherapeutics and therefore provide the fundament for novel approaches circumventing chemoresistance with salinomycin.

\section{Acknowledgements}

The authors want to thank Bianca Köhler for excellent technical support. Adam Hermawan received a doctoral fellowship from the Islamic Development Bank, IDB (28/IND/P32; Student ID 600014391).

\section{References}

1. Stewart BW and Wild CP (eds): World Cancer Report 2014 International Agency for Research on Cancer, WHO, Lyon, 2015.

2. Hryniewicz-Jankowska A, Augoff K, Biernatowska A, Podkalicka J and Sikorski AF: Membrane rafts as a novel target in cancer therapy. Biochim Biophys Acta 1845: 155-165, 2014.

3. Al Saleh S, Sharaf LH and Luqmani YA: Signalling pathways involved in endocrine resistance in breast cancer and associations with epithelial to mesenchymal transition (Review). Int J Oncol 38: 1197-1217, 2011.

4. Chuthapisith S, Eremin J, El-Sheemey M and Eremin O: Breast cancer chemoresistance: Emerging importance of cancer stem cells. Surg Oncol 19: 27-32, 2010.

5. Malenfant SJ, Eckmann KR and Barnett CM: Pertuzumab: A new targeted therapy for HER2-positive metastatic breast cancer. Pharmacotherapy 34: 60-71, 2014.

6. Piccart M: Circumventing de novo and acquired resistance to trastuzumab: New hope for the care of ErbB2-positive breast cancer. Clin Breast Cancer 8 (Suppl 3): S100-S113, 2008.

7. O'Driscoll L and Clynes M: Biomarkers and multiple drug resistance in breast cancer. Curr Cancer Drug Targets 6: 365-384, 2006.

8. Gonzalez-Angulo AM, Morales-Vasquez F and Hortobagyi GN: Overview of resistance to systemic therapy in patients with breast cancer. Adv Exp Med Biol 608: 1-22, 2007.

9. Gupta PB, Onder TT, Jiang G, Tao K, Kuperwasser C, Weinberg RA and Lander ES: Identification of selective inhibitors of cancer stem cells by high-throughput screening. Cell 138: 645-659, 2009.

10. Arafat K, Iratni R, Takahashi T, Parekh K, Al Dhaheri Y, Adrian TE and Attoub S: Inhibitory effects of salinomycin on cell survival, colony growth, migration, and invasion of human non-small cell lung cancer A549 and LNM35: Involvement of NAG-1. PLoS One 8: e66931, 2013.

11. AlDhaheri Y, Attoub S, Arafat K, Abuqamar S, Eid A, Al Faresi N and Iratni R: Salinomycin induces apoptosis and senescence in breast cancer: Upregulation of p21, downregulation of survivin and histone $\mathrm{H} 3$ and $\mathrm{H} 4$ hyperacetylation. Biochim Biophys Acta 1830: 3121-3135, 2013.

12. Koo KH, Kim H, Bae YK, Kim K, Park BK, Lee CH and Kim YN: Salinomycin induces cell death via inactivation of Stat3 and downregulation of Skp2. Cell Death Dis 4: e693, 2013.

13. Li T, Su L, Zhong N, Hao X, Zhong D, Singhal S and Liu X: Salinomycin induces cell death with autophagy through activation of endoplasmic reticulum stress in human cancer cells. Autophagy 9: 1057-1068, 2013.

14. Ketola K, Hilvo M, Hyötyläinen T, Vuoristo A, Ruskeepää AL, Orešič M, Kallioniemi $\mathrm{O}$ and Iljin K: Salinomycin inhibits prostate cancer growth and migration via induction of oxidative stress. Br J Cancer 106: 99-106, 2012.

15. Schenk M, Aykut B, Teske C, Giese NA, Weitz J and Welsch T: Salinomycin inhibits growth of pancreatic cancer and cancer cell migration by disruption of actin stress fiber integrity. Cancer Lett 358: 161-169, 2015.
16. Kopp F, Hermawan A, Oak PS, Herrmann A, Wagner E and Roidl A: Salinomycin treatment reduces metastatic tumor burden by hampering cancer cell migration. Mol Cancer 13: 16, 2014.

17. Fuchs D, Daniel V, Sadeghi M, Opelz G and Naujokat C: Salinomycin overcomes ABC transporter-mediated multidrug and apoptosis resistance in human leukemia stem cell-like KG-1a cells. Biochem Biophys Res Commun 394: 1098-1104, 2010.

18. Fuchs D, Heinold A, Opelz G, Daniel V and Naujokat C: Salinomycin induces apoptosis and overcomes apoptosis resistance in human cancer cells. Biochem Biophys Res Commun 390: 743-749, 2009.

19. Kim JH, Chae M, Kim WK, Kim YJ, Kang HS, Kim HS and Yoon S: Salinomycin sensitizes cancer cells to the effects of doxorubicin and etoposide treatment by increasing DNA damage and reducing p21 protein. Br J Pharmacol 162: 773-784, 2011

20. Liffers ST, Tilkorn DJ, Stricker I, Junge CG, Al-Benna S, Vogt M, Verdoodt B, Steinau HU, Tannapfel A, Tischoff I, et al: Salinomycin increases chemosensitivity to the effects of doxorubicin in soft tissue sarcomas. BMC Cancer 13: 490, 2013.

21. Zhou J, Li P, Xue X, He S, Kuang Y, Zhao H, Chen S, Zhi Q and Guo X: Salinomycin induces apoptosis in cisplatin-resistant colorectal cancer cells by accumulation of reactive oxygen species. Toxicol Lett 222: 139-145, 2013.

22. Zhang B, Wang X, Cai F, Chen W, Loesch U and Zhong XY: Antitumor properties of salinomycin on cisplatin-resistant human ovarian cancer cells in vitro and in vivo: Involvement of p38 MAPK activation. Oncol Rep 29: 1371-1378, 2013.

23. Calzolari A, Saulle E, De Angelis ML, Pasquini L, Boe A, Pelacchi F, Ricci-Vitiani L, Baiocchi M and Testa U: Salinomycin potentiates the cytotoxic effects of TRAIL on glioblastoma cell lines. PLoS One 9: e94438, 2014.

24. Oak PS, Kopp F, Thakur C, Ellwart JW, Rapp UR, Ullrich A, Wagner E, Knyazev P and Roidl A: Combinatorial treatment of mammospheres with trastuzumab and salinomycin efficiently targets HER2-positive cancer cells and cancer stem cells. Int J Cancer 131: 2808-2819, 2012.

25. Kim KY, Kim SH, Yu SN, Park SK, Choi HD, Yu HS, Ji JH, Seo YK and Ahn SC: Salinomycin enhances doxorubicininduced cytotoxicity in multidrug resistant MCF-7/MDR human breast cancer cells via decreased efflux of doxorubicin. Mol Med Rep 12: 1898-1904, 2015.

26. Kopp F, Oak PS, Wagner E and Roidl A: miR-200c sensitizes breast cancer cells to doxorubicin treatment by decreasing TrkB and Bmil expression. PLoS One 7: e50469, 2012.

27. Kopp F, Hermawan A, Oak PS, Ulaganathan VK, Herrmann A, Elnikhely N, Thakur C, Xiao Z, Knyazev P, Ataseven B, et al: Sequential salinomycin treatment results in resistance formation through clonal selection of epithelial-like tumor cells. Transl Oncol 7: 702-711, 2014

28. Dönmez Y, Akhmetova L, İşeri OD, Kars MD and Gündüz U: Effect of MDR modulators verapamil and promethazine on gene expression levels of $M D R 1$ and $M R P 1$ in doxorubicin-resistant MCF-7 cells. Cancer Chemother Pharmacol 67: 823-828, 2011.

29. Latorre E, Tebaldi T, Viero G, Spartà AM, Quattrone A and Provenzani A: Downregulation of HuR as a new mechanism of doxorubicin resistance in breast cancer cells. Mol Cancer 11: 13, 2012.

30. Lin ST, Chou HC, Chang SJ, Chen YW, Lyu PC, Wang WC, Chang MD and Chan HL: Proteomic analysis of proteins responsible for the development of doxorubicin resistance in human uterine cancer cells. J Proteomics 75: 5822-5847, 2012.

31. Qinghong S, Shen G, Lina S, Yueming Z, Xiaoou L, Jianlin W, Chengyan $\mathrm{H}$, Hongjun $\mathrm{L}$ and Haifeng Z: Comparative proteomics analysis of differential proteins in respond to doxorubicin resistance in myelogenous leukemia cell lines. Proteome Sci 13: 1, 2015.

32. Zhou Y, Liang C, Xue F, Chen W, Zhi X, Feng X, Bai X and Liang T: Salinomycin decreases doxorubicin resistance in hepatocellular carcinoma cells by inhibiting the $\beta$-catenin/TCF complex association via FOXO3a activation. Oncotarget 6: 10350-10365, 2015.

33. Cahill DP, Kinzler KW, Vogelstein B and Lengauer C: Genetic instability and Darwinian selection in tumours. Trends Cell Biol 9: M57-M60, 1999.

34. Israeli D, Ziaei S, Gonin P and Garcia L: A proposal for the physiological significance of mdr1 and Bcrp1/Abcg2 gene expression in normal tissue regeneration and after cancer therapy. J Theor Biol 232: 41-45, 2005. 
35. Katayama K, Yoshioka S, Tsukahara S, Mitsuhashi J and Sugimoto Y: Inhibition of the mitogen-activated protein kinase pathway results in the down-regulation of P-glycoprotein. Mol Cancer Ther 6: 2092-2102, 2007.

36. Zhou S, Schuetz JD, Bunting KD, Colapietro AM, Sampath J, Morris JJ, Lagutina I, Grosveld GC, Osawa M, Nakauchi H, et al: The ABC transporter Bcrp1/ABCG2 is expressed in a wide variety of stem cells and is a molecular determinant of the sidepopulation phenotype. Nat Med 7: 1028-1034, 2001.

37. Doyle L and Ross DD: Multidrug resistance mediated by the breast cancer resistance protein BCRP (ABCG2). Oncogene 22: 7340-7358, 2003.

38. Xiang W, Gao A, Liang H, Li C, Gao J, Wang Q, Shuang B, Zhang J, Yan Y and Wang X: Reversal of P-glycoprotein-mediated multidrug resistance in vitro by milbemycin compounds in adriamycin-resistant human breast carcinoma (MCF-7/adr) cells. Toxicol In Vitro 24: 1474-1481, 2010.

39. Hoffmann EK and Lambert IH: Ion channels and transporters in the development of drug resistance in cancer cells. Philos Trans R Soc Lond B Biol Sci 369: 20130109, 2014.

40. Drori S, Eytan GD and Assaraf YG: Potentiation of anticancerdrug cytotoxicity by multidrug-resistance chemosensitizers involves alterations in membrane fluidity leading to increased membrane permeability. Eur J Biochem 228: 1020-1029, 1995.

41. Bissinger R, Malik A, Jilani K and Lang F: Triggering of erythrocyte cell membrane scrambling by salinomycin. Basic Clin Pharmacol Toxicol 115: 396-402, 2014.
42. Mitani M, Yamanishi T, Miyazaki Y and Otake N: Salinomycin effects on mitochondrial ion translocation and respiration. Antimicrob Agents Chemother 9: 655-660, 1976.

43. Matsumori N, Morooka A and Murata M: Conformation and location of membrane-bound salinomycin-sodium complex deduced from NMR in isotropic bicelles. J Am Chem Soc 129: 14989-14995, 2007.

44. Boehmerle W and Endres M: Salinomycin induces calpain and cytochrome $c$-mediated neuronal cell death. Cell Death Dis 2: e168, 2011.

45. Moitra K, Lou H and Dean M: Multidrug efflux pumps and cancer stem cells: Insights into multidrug resistance and therapeutic development. Clin Pharmacol Ther 89: 491-502, 2011.

46. Bunting KD: ABC transporters as phenotypic markers and functional regulators of stem cells. Stem Cells 20: 11-20, 2002.

47. Yusa $\mathrm{K}$ and Tsuruo $\mathrm{T}$ : Reversal mechanism of multidrug resistance by verapamil: Direct binding of verapamil to P-glycoprotein on specific sites and transport of verapamil outward across the plasma membrane of K562/ADM cells. Cancer Res 49: 5002-5006, 1989.

48. Minotti G, Menna P, Salvatorelli E, Cairo G and Gianni L: Anthracyclines: Molecular advances and pharmacologic developments in antitumor activity and cardiotoxicity. Pharmacol Rev 56: 185-229, 2004. 